THE CRIMTAL AND THE Connexity.

Prison Surgeos. - The following books mar serve our correspondent's purpose : Crime : Its Canse and liemedies, by Cesare Lombroso, translated by H. F. Horton (16s. net); Criminal I'sychology, by Hans Gross, translated from the four th German edition by H. M. Kallen (17s. net); Iole'n Theorie's of Criminality, by B. Bernaldo de Quiros, translated from the Spanish by Alfonso de Salvio (14s. net), all in the Modern Criminal Science Series, published by Heinemann; The Criminal Science Series, published by Heinemann; The Crime and the Community, by James Devon, published by John Lane (5s. net) ; Crime
lighed by Longmais.

\section{NaIL Biting}

M. C. W. writes: In reply to "M. J. M." there is only one way to cure biting nails : Give the offender a nice sinall pair of nail scissors, and insist upon their being always kept in readiness in the pocket and used constantly, never allowing any roughmess of the nails to remain. Rigidly keep to this, offender may be.

\section{LETTERS, NOTES, ETC.}

ShIP SURGEONS.

Novice who, lured, as he states, by glowing accounts of the sunny south, recently acted as surgeon to a ship for a nominal salary of 1s. a month, warns other young practitioners from following his example. He found his quarters ver uncomfortable, and learnt that most such boats were in reality cargo boats taking passengers, and might be detained at the port of destination for weeks longer than the advertised time in order to pick up cargo. Medical men, however, who choose to give their services for a shilling a month and their board deserve, their services for a shilling a month and thei
many will think, what ther get and no more.

P. AND O. SuRGEON writes to advise all qualified men who have any idea of going into the mercantile marine for a livelihood or for a voyage or two, to insist upon being supplied with a copy of the regulations which apply to them before joining, and also upon obtaining proper acroinmodation on board. He quotes the following regulation, which he has found irksome :

Reg. X.-Executive officers are not permitted to participate in the amusements of passengers, such as games, etc. They will confine themselves to politeness and courtesy to passengers when cof sation with passengers, although courtesy dictates a polite reply to an inguiry.

Strictly read, he said, the surgeon is by this resolution forbidden to form acquaintances among the passengers, has no opportunity of exercise, since the decks are taken up by the passengers, and therefore is compelled to spend the bulk of his time in his cabin, which is frequently dark and without ventilation.

RESUSCitation OF THE STILLBOR:

DR. Alexander DUke (London) writes: The description by Dr. H. Stokes of his plan for resuscitation of a stillborn child is so like the plan I described and practised myself with marked success nearly twenty rears ago that I may be pardoned for describing it. (I copr description from a printed pardoned for describing it. (I copr description from a printed 1892.) "I first of all clear mucus from mouth of infant, and then pass finger into pharrnx and endeavour to open up 'atmospheric highwar.' I then at once lay the infant face downwards across the palm of my right hand, the tips of ingers over cardia region, so as to detect at once improvement in the beat of heart. With the hand uncler thorax compress the ribs (as one would a rubber bellows) at intervals of ten seconds, measured by counting. The head and chest being kept at lower level than the pelvis favours the gravitation of blood to the brain, and also the exit of any mucus from mouth. When I find the action of heart improve I plunge the infant into hot water, keeping $u_{1}$, the rhrthmical compression of ribs all the time infant is in the water ifive minutes, as a rule, I found sufficient), and direct the nurse in attendance to lash a little cold water over back and shoulders, which is soon followed by gasping and infantile crr, the former most important, as when neglected it is of ten the primar. most important, as when neglected it is often the primary Stokes's description to my plan, which I have nerer found to Stokes's description to my plan, which I have never found to
fail I could distinguish any cardia action (even the faintest), must be my excuse for asking the favour of publication in the BRITISH MEDICAL JOURNAL.

Fatal Ixtraperitoseal Handorrhage from the VITElline Veis.

). W. Harold Beterley (Barnsley writes: On Norember 2nd I was called to see a child in extremis. On arrival at the house at 6.30 a.m. I was shorn a newborn female child. On exami. nation I found life extinct, the legs and ams covered rith a cold perspiration, the lips pale. There was no rigidity of the limbs; the cord was properly tied, $2 \frac{1}{1}$ in. from the unibilicus. There were no external signs of violence. A midwife attended the labour at $11.15 \mathrm{p} . \mathrm{m}$. on the previous dav. The birth was unite natural, head first, occiput to the left front, no difficulty with the shoulders. The midrife requiring no medical hielp, finsisherl her work, and left the house at $1 \mathrm{a.m}$. on November 2 nd. She was called again at 5.30 , and on finding the child :eriously ill, sent for me. but the infant expired thee minutes before my arrial. The post-mtrtem examina. tion showed the body well-nourished. On making the median incision the peritoneal cavity, before it was opened, appeared to contain blood. The incision was carried down on the splenic sicle of the umbilicus. On opening the peritoneal cavity a quantity of blood clot was found on the right side up to the liver, in the right loin, and in the pelvis. The left loin was quite frec. The liver, spleen, kidners, stomach, ininside the abdomen, at the umbilicus, the Vitelline vein was cleanly severed transverely; as if by a sharp knife, for abcut $\frac{1}{6}$ in. No other injury could be found. At the inquest the midwife denied any traction on the cord or any prolapse of same prior to birth.

Infantile Paralysis.

Dr. D. MCNicol (Glasgow), writes: In view of the very serious outbreak of anterior poliomyelitis in different counties of Fngland, reported in BRITISH MFDICAL Journal with the discussions and theories as to etiology, etc., I should like to report the following case

The house in which the case occurred was not in Glasgow, but abuts on a main road, the traffic over which is greatmotors largely. The patient is a bright, active girl, aged 2 years and 5 months, supposed to be "too intelligent for her. age." The illness began on September 19th, 1911. Slowly she got cross and peevish and irritable and slightly feverisi and very constipated; there was no sickness or vomiting: and very constipated; there was no sickness or vomiting; sleep was broken and restlessness great-that was all. On there was not much wrong beyond a cold, etc., and prescribed there was not much wrong beyond a cold, etc., and prescribed
something. The child ran about the kitchen for a time when something. The child ran about the kitchen for a time when
she came back, then asked to be put to bed. Next morning, September 24th, she "couldn't stand." The affection was then supposed to be rheumatism, and the doctor who saw her on September 24th and 25th is stated on the latter day to have said that the urine on that day resembled that of an old man with gout, the quantity of urie acid crystals being so great. The child, I am told, at this time screamed out when grasped to lift her up, held herself stiff and straight out, and "couldn't sit" on a seat or on her mother's knee (that is, opisthotonos). She vomited one day, but only a little curdled milk. This condition lasted a week. Improvement began in the third week, slowly. I saw the case at the beginning of the third week, slowly. I saw the case at the beginning of
the fifth week. The child was quite well and happy, and the fifth week. The child was quite well and happy, and
sitting playing with toys in bed. The condition of the right sitting playing with toys in bed. The condition of the right leg was as follows: The muscles of the right thigh and leg were soft, atrophied distinctly, and very flaccid ; the circum-
ference of the thigh was 1 in. less and that of the calf of the leg $\frac{3}{4} \mathrm{in}$. less than the other. She could move it about from the knee when sitting, but could not raise it up, and she conld not keep it straight anter when standing. Although wrapped up in a flannel bandage, the surface was colder then the other leg, which was bare. Sensation was normal. I prescribed arsenic and natural sodium salicylate, and suggested she should be well fed ; raw meat juice, mill, white of egg, Allenbury's food, bread and butter, light and clear soups; bath every night (sea salt), followed by rubbing; massage of muscles of the leg and weak galvanic current for three minutes daily to besin with. Three weeks later, the eightl after the illness began, power is coming back to leg, which after the illness began, power is coming back to leg, which feels much firmer and not so cold, she can raise it up, and is nearly able to let it fall gradually, but

If this should meet the eye of some man who has treater a
If number of these cases to a finish, I should be glad to hear any suggestions as to whether electricity, high-frequency current or other, would help. I tested the hip-joint thoroughly, so as to eliminate morbus coxae. Spinal meningitis, too, I thought of, but a careful description of the illness from the parents, and, above all, the swiftness of the paralysis and its completeness, negatived that too. I am publishing this case to warm men in this country of the possibility of cases turning up in their practice, so that they may uorthern latitude, and seeing that it is now the cold season.

\section{ERRATUM.}

We regret that, in the list of contents of the Journal of December 2nd, the qualifications of Dr. Watkin W. Jones, who contributed a letter on the treatment of obesity, were incorrectly given as M.R.C.S., L.R.C.P.- his correct qualifications are M.D., F.F.P.S., L.S.A.

GCALE OF CHARGES FOR ADYERTIBEMENTS IN THE BRITIBH MEDICEL JOURNAY.

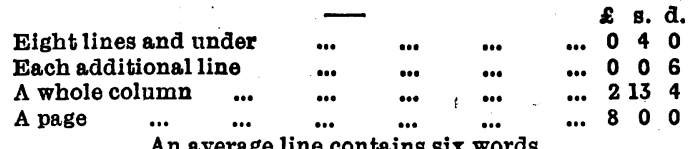

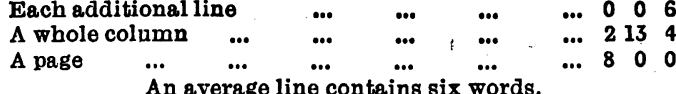

All remittances by Post Office Orders must be made payable to the British Nedical Association at the General Post Office, London. No responsibility will be accepted for any such remittance not so
safeguarded. Advertisements should be delivered, addressed to the Manager, 429, Strand, London, not later than the first post on Wednesday morning ccompanied by a reference.

Note.-It is against the rules of the Post Office to receive postes restante letters addressed either in initials or numbers. 